Final Report

Project Title: Engineered Nanostructured MEA Technology for Low Temperature Fuel Cells

Project Period: August 21, 2008 to July 13, 2009

Date of Report: July 13, 2009

Recipient: Nanosys, Inc.

Award Number: DE-FG36-08G088097

Working Partners: Nanosys, Inc

Cost-Sharing Partners: Nanosys, Inc

Technical Contact: Yimin Zhu, 650-331-2232, yzhu@nanosysinc.com

Business Contact: Michelle Chan, 650-331-2194, mchan@nanosysinc.com

DOE Managers: Greg Kleen (DOE Project Officer); Scott Salvati (DOE Project

Monitor)

Project Objective:

The objective of this project is to develop a novel catalyst support technology based on unique engineered nanostructures for low temperature fuel cells which

- Achieves high catalyst activity and performance

- Improves catalyst durability over current technologies

- Reduces catalyst cost

\title{
Technical Barriers
}

This project addresses the following technical barriers from the Fuel Cells section of the Hydrogen, Fuel Cells and Infrastructure Technologies Program Multi-Year Research, Development and Demonstration Plan (HFCIT):
(A) Performance
(B) Durability

\section{Technical Targets}

This project is directed at the development of durable catalysts supported by novel support that improves the catalyst utilization and hence reduce the catalyst loading. This project will develop a solid fundamental knowledge base necessary for the synthetic effort while at the same time demonstrating the catalyst advantages in DMFCs. If successful, the project will address the following DOE technical targets as outlined in the HFCIT Multi-Year RD\&D Plan:

This project is conducting fundamental studies of nanowire supported catalysts applied in fuel cells. Insights gained from these studies will be applied to DMFCs first to demonstrate the catalyst advantages over commercial carbon supported catalysts, prior to eventual demonstration in hydrogen fuel cells:

- $>60 \mathrm{~mW} / \mathrm{cm}^{2}$ at $40^{\circ} \mathrm{C}$, ambient condition

- Demonstrate durability advantage, $<60 \mu \mathrm{A} / \mathrm{h}$ 


\section{Accomplishments}

- Produced Si nanowire with a diameter as small as $30 \mathrm{~nm}$

- Converted Si nanowire to graphite/SiC nanowire with high surface area of $125 \mathrm{~m}^{2} / \mathrm{g}$ (BET)

- Controlled Pt alloy particle size in the range of $1.5 \sim 3 \mathrm{~nm}$, average $2 \mathrm{~nm}$

- Uniformly deposited Pt alloy nanoparticles on nanowire support

- Achieved $>112 \mathrm{~mW} / \mathrm{cm}^{2}$ (2x of target) with nanowire catalysts-based MEA at ambient condition \& $40^{\circ} \mathrm{C}$ for $3 M$ DMFCs, which is $45 \mathrm{~mW} / \mathrm{cm}^{2}$ better than that with commercial catalyst.

- Achieved durability of over 1,000 hours with $9 \mu \mathrm{V} / \mathrm{hr}$ decay rate (equiv. 6.5x of target)

Background: Fuel cells are an electrochemical device that converts the chemical energy of a fuel into electricity. In the case of Direct Methanol Fuel Cells (DMFCs), the conversion of the fuel source to energy occurs at the Membrane Electrode Assembly (MEA) within each individual cell in a fuel cell stack. The MEA contains the catalysts critical to the process which promote the electrochemical reactions such as oxidation of hydrogen or methanol and reduction of oxygen. For most fuel cell designs, the catalyst with the best performance properties to date is made of the precious metal Platinum (Pt) or its compounds. However, in today's fuel cells, the level of precious metal utilization using supported catalysts in the MEA is extremely low, around $20-30 \%$. This low catalyst utilization represents a major barrier towards lowering the cost (particularly since Pt has costs $>\$ 1,000$ per ounce) and improving the performance of fuel cells - two critical factors for the commercialization of this technology. In particular, in a traditional packed-particle composite used in today's MEAs, the majority of catalyst nanoparticles are lost due to agglomeration of the support particles that leave them inaccessible to the fuel source or the ionic conductor for catalysis reaction in the catalyst layer. Additional efficiency is lost when catalyst particles are located such that they are in poor electrolytic contact with the proton exchange membrane (PEM) or poor electrical contact with the electrode through the support matrix. Each of these elements impacts overall efficiency of the MEA and therefore the resulting fuel cell.

The US DOE develops four strategies to address challenges in catalysts \& support materials, which are:

- Lower PGM content: improved Pt utilization and durability

- Pt alloys: maintain/improve performance and reduce cost

- Novel support structures: Non-carbon supports and alternative carbon structures

- Non-Pt catalysts: maintain performance and durability

For this project, Nanosys focused on strategy \# 3 . We are to develop a novel catalyst support technology based on unique engineered nanostructures for low temperature fuel cells which

- Achieves high catalyst activity and performance

- Improves catalyst durability over current technologies

- Reduces catalyst cost 
Through precise control of the nanowire density, diameter, length, surface chemistry, catalyst deposition density and sulfonic acid group density of polymer electrolyte, we will be able to independently control and optimize each of the most important elements of the MEA, including porosity, electrical connectivity, electrolyte connectivity and catalyst accessibility. This level of control is not possible with traditional packed-bed MEAs and will allow us to fabricate MEAs in which majority of the catalyst material is accessible and active.

\section{Task 1.0: Advanced Nanowire Materials Development}

We have grown silicon nanowires on the surface of a substrate using a colloidal catalyst based VLS synthesis method. $\mathrm{SiH}_{4}$ is used as the growth gas. The diameter is controlled within $30 \sim 40 \mathrm{~nm}$. Next, the silicon nanowires are directly converted at high temperature into $\mathrm{SiC}$ coated with nanographite shell. The core/shell nanowires have been characterized using transmission electron microscopy (TEM) and/or scanning electron microscopy (SEM) to evaluate overall nanowire morphology and structure, as shown in Figure 1. After the high temperature process the crystallinity and nanowire structure are retained (Figure 1A. TEM studies have shown this graphite shell is covalently bonded onto the surface of the SiC nanowires. Two key factors, high crystallinity and covalent bonding between nanographite and $\mathrm{SiC}$, make this support much more stable than poorly crystallized carbon black support. The final core-shell nanowires have diameters as small as 30 nanometers and aspect ratios of $\sim 100: 1$. The nanographite shell with barbs (Figure 1B) makes the nanowire material have good electrical conductivity. This also results in a large surface area of ca. $125 \mathrm{~m}^{2} / \mathrm{g}$, measured by BET.
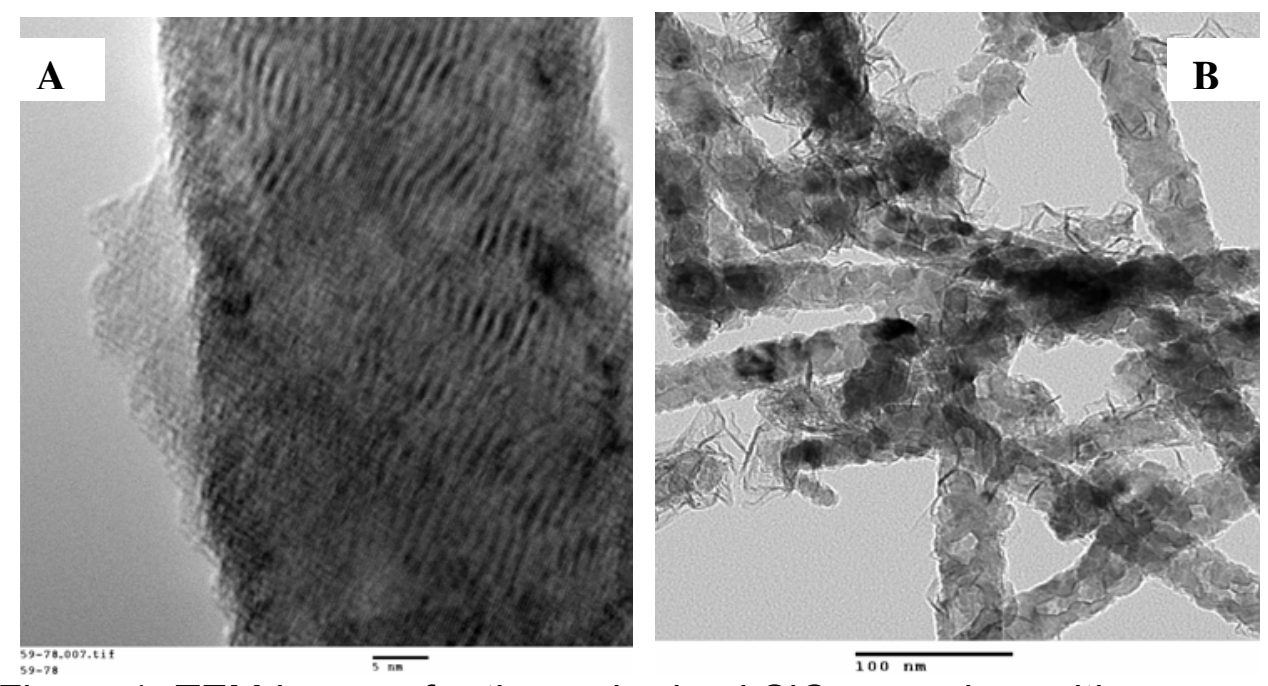

Figure 1. TEM images for the carburized $\mathrm{SiC}$ nanowires with nanographite shell. A. HRTEM for identifying crystallinity; B. Nanographite barbs on SiC nanowires

In Task 1.0, the electrically conductive nanowires have been made with high surface area of $125 \mathrm{~m}^{2} / \mathrm{g}$. 


\section{Task 2.0: Catalyst Nanoparticle Fabrication}

We have prepared free-standing well-dispersed nanoparticles using a solution phase process method. This has been accomplished by dispersing metal precursor materials in a solvent (such as ethlyene glycol), and controlling the reduction rate of the precursors. By controlling the reaction temperature profile and ratio of starting reagents and conditions, the particle size, size-distribution and composition have been tuned independently. EDX analysis has confirmed the ratio of Pt and Ru is ca. 1 to 1 . XRD results indicate that the particle size of the metallic PtRu particles can be controlled from 1 to $5 \mathrm{~nm}$. Typically, we prepared the PtRu particles with an average particle size of $2 \mathrm{~nm}$. TEM analysis showed that well-dispersed PtRu nanoparticles have an average particle size of ca. $2 \mathrm{~nm}$, as shown in Figure 2.
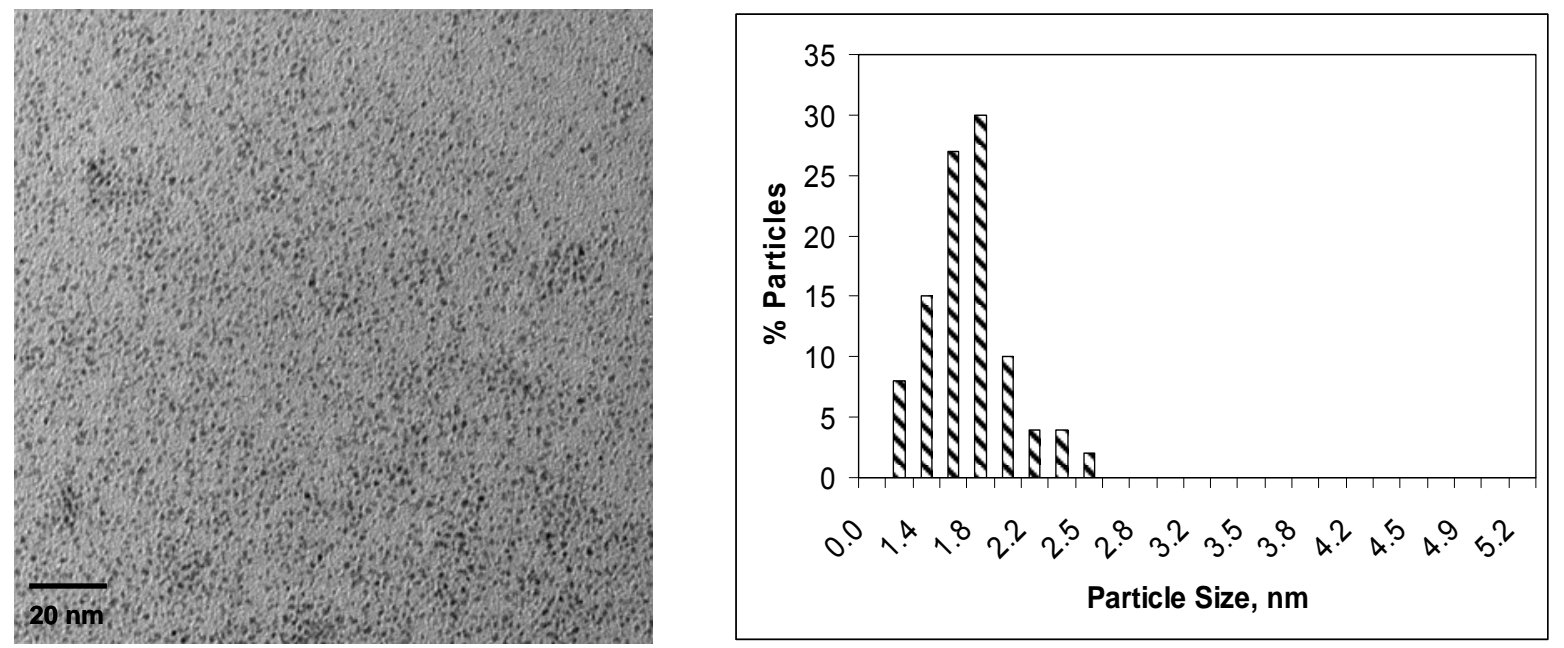

Figure 2 Left: TEM image for PtRu nanoparticles; Right: particle size distribution

Task 2.0 has been completed. A process has been established to produce welldispersed catalyst nanoparticles. The particle size is in the range of $1.5 \sim 3 \mathrm{~nm}$ with an average size of ca. $2 \mathrm{~nm}$.

\section{Task 3.0 Catalyst Integration onto nanowire support}

We have successfully developed a method to integrate the nanoparticle catalysts onto the nanowire supports by dispersing the nanowire support materials prepared in Task 1 in ethylene glycol and then adding the nanoparticles from task 2. By inducing electrostatic attraction between the nanoparticles and the nanowires, this integration is quite strong for the relative size of the nanoparticles and nanowires. After removing all the solvent and impurities, the nanowire supported catalyst is vacuum-dried to yield a final catalyst, typically $30 \%$ PtRu on nanowire support. The uniform distribution of nanoparticles on the surface of the nanowire support has been observed by TEM, as shown in Figure 3. The small particle size has been retained. 


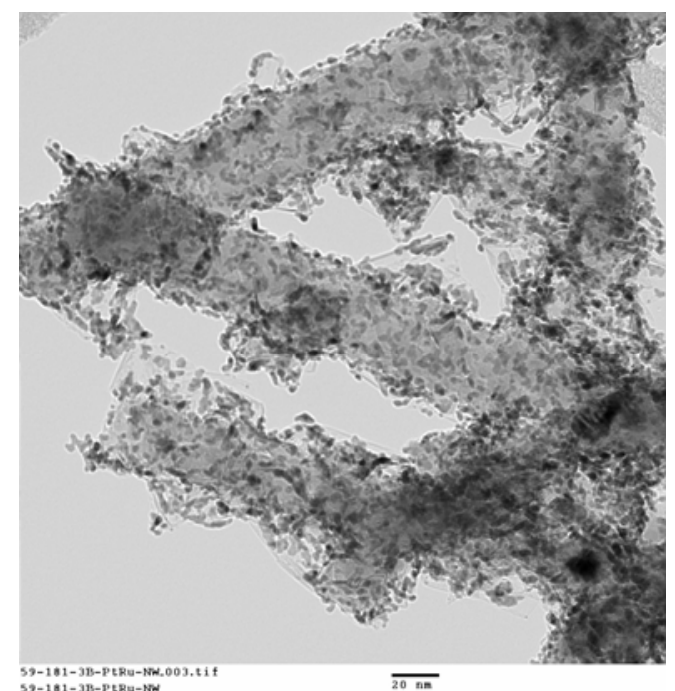

Figure 3 TEM image for PtRu distribution on nanowire support.

Table 1: Catalyst nano-particle characteristic

\begin{tabular}{|c|c|c|c|}
\hline & $\begin{array}{c}\text { Dia. } \mathrm{nm} \\
\text { XRD }\end{array}$ & $\begin{array}{c}\text { Dia, } \mathrm{nm} \\
\text { TEM }\end{array}$ & d spacing $\mathrm{nm}$ \\
\hline PtRu/NW & 2.7 & 2.1 & 0.236 \\
\hline Pt/C ref. & 3.2 & 3.0 & 0.241 \\
\hline
\end{tabular}

The obtained metallic PtRu particles on nanowires have a particle size of ca. $2.7 \mathrm{~nm}$, measured by XRD, and ca. $2.1 \mathrm{~nm}$, measured by TEM. The $d$-spacing of reflexion (index) decreased with increasing Ru content and annealing temperature, resulting from the replacement of Pt atoms on the lattice points of the f.c.c. by the smaller Ru atoms.

The activity and performance for a methanol oxidation reaction at the nanowire supported PtRu catalyst has been characterized in a three-electrode electrochemical cell at $40^{\circ} \mathrm{C}$. At $0.5 \mathrm{~V}$, the mass current for methanol oxidation at PtRu/NW is ca. $2.5 \mathrm{x}$ higher than that at PtRu/C (commercial), which clearly indicates PtRu/NW advantage in activity for methanol oxidation over PtRu/C. 


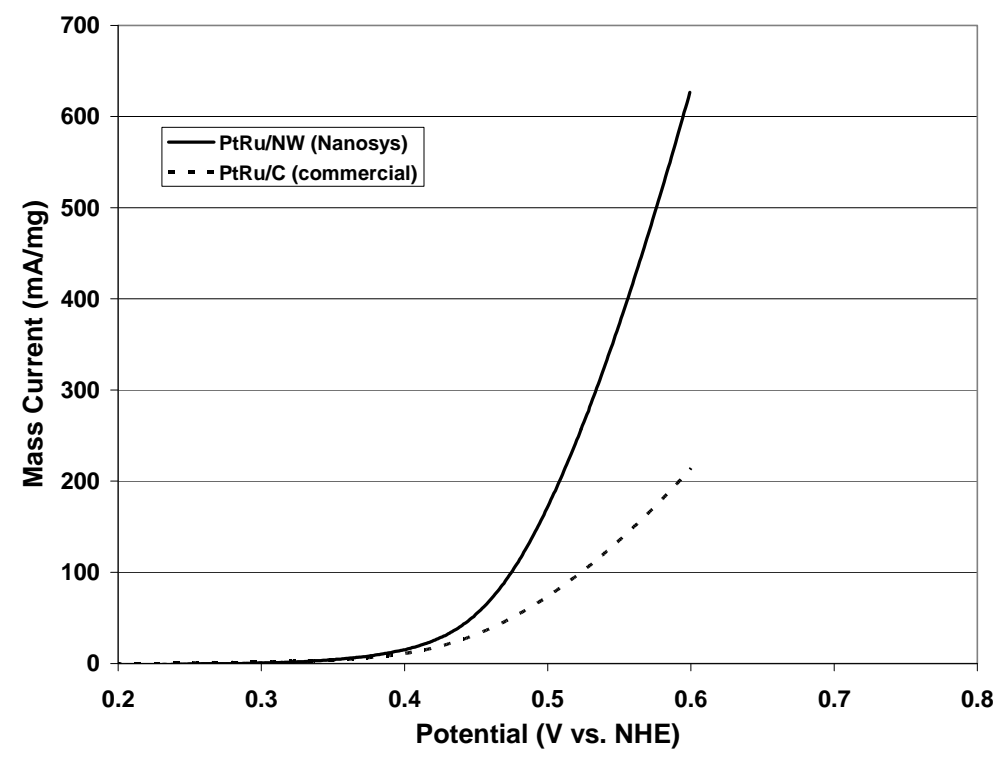

Figure 4 Mass current $\sim$ Potential for methanol oxidation at PtRu/NW and PtRu/C. 3M methanol $+0.5 \mathrm{M} \mathrm{H}_{2} \mathrm{SO}_{4}, 40^{\circ} \mathrm{C}$.

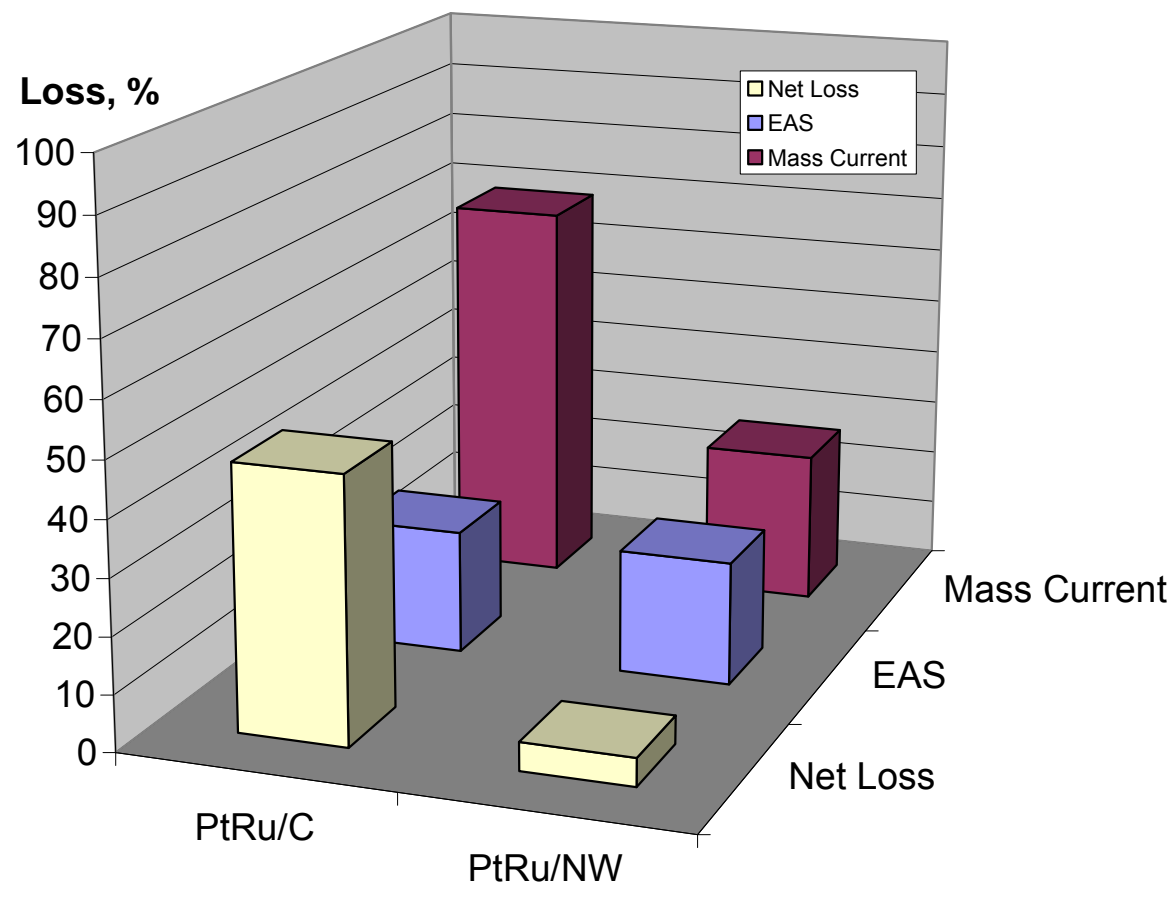

Figure 5 Stability of PtRu/NW catalysts. Potential cycling from $0.05-0.6 \mathrm{~V}>3200$ cycles 
The stability of PtRu/NW catalyst for methanol oxidation has been measured by cycling potential between $0.05 \mathrm{~V}$ and $0.6 \mathrm{~V}$ for 3200 cycles. The loss in mass current measured at $0.5 \mathrm{~V}(27 \%)$ is much lower than that of $69 \%$ for commercial PtRu/C catalyst under the identical condition. The losses in electrochemically active surface area (EAS) are similar for both PtRu/NW and PtRu/C catalysts ( 22\%), which may indicate comparable defoliating and coalescing of the catalysts. We may assume the net loss in mass activity can be evaluated by the difference between the measured mass current loss and the EAS loss. Therefore, only $5 \%$ loss is for PtRu/NW, which is much lower than that of $47 \%$ for PtRu/C catalyst, as shown in Figure 5.

In Task 3.0, a process has been developed to uniformly deposit catalyst nanoparticles on nanowire supports with catalyst loadings of $20 \%$ to $40 \%$ and particle sizes between 1.5 to $3 \mathrm{~nm}$. It has been demonstrated that PtRu/NW has significant advantage of the activity for methanol oxidation over commercial PtRu/C catalysts. The stability of $\mathrm{PtRu} / \mathrm{NW}$ has also been evaluated.

\section{Task 4.0: MEA Development}

A catalyst coated membrane method and a 5-layer MEA method are used to fabricate MEAs with nanowire supported PtRu catalysts or carbon supported PtRu catalyst. Formulation of nanowire catalyst, proton exchange polymer ionomer, and dispersion solvents has been optimized. The nafion ionomer with lower equivalent weight (EW1000) has been used for the nanowire supported catalyst.

Using the nanowire catalysts, commercially available gas diffusion layer and Polyfuel hydrocarbon membranes, MEAs of $5 \mathrm{~cm}^{2}$ active area are fabricated for the catalyst performance evaluation.
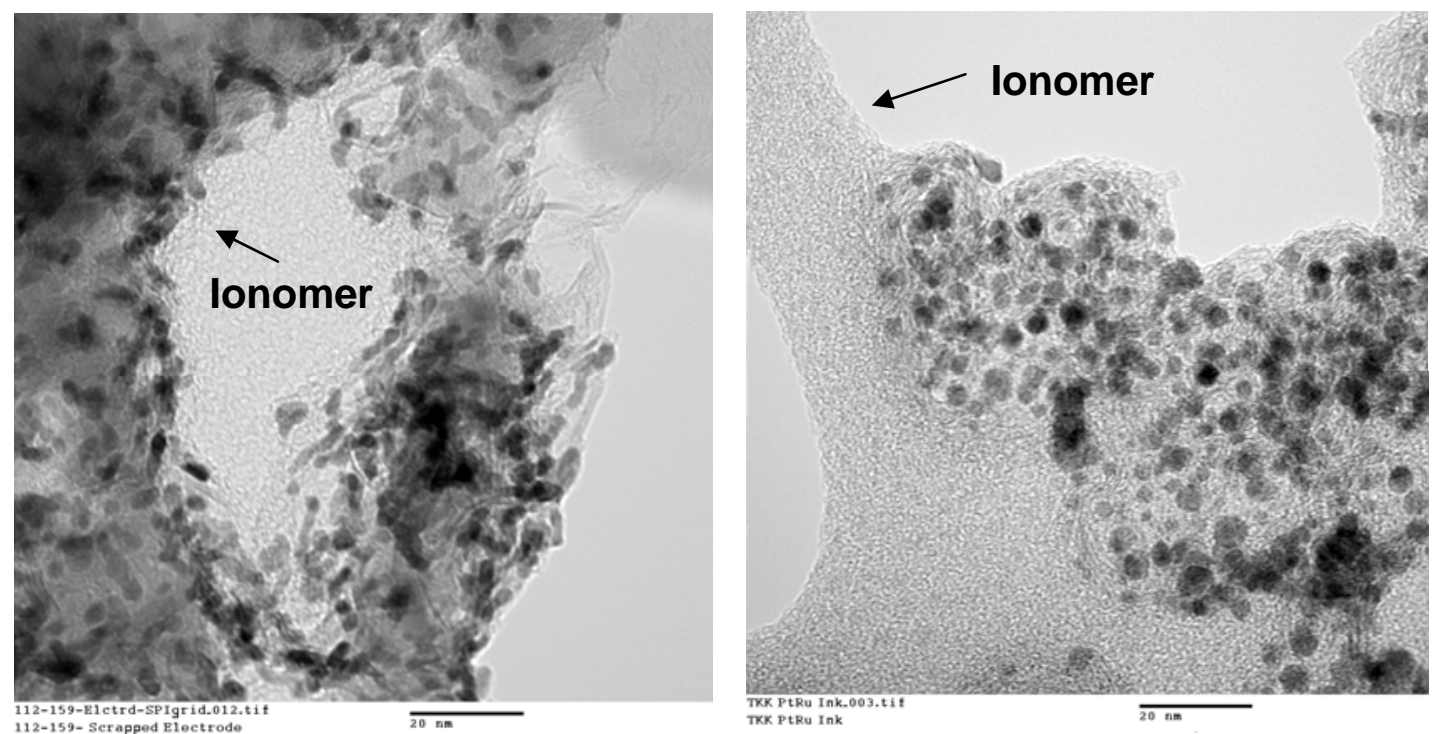

Figure 6 TEM image of the scraped sample from PtRu/NW+ionomer anode catalyst layer of MEA (A) or from PtRu/C+ionomer anode catalyst layer of MEA (B). 
The porosity of nanowire supported catalyst layer is relatively larger than that of carbon supported catalyst layer in MEAs so that ionomer can be uniformly distributed in the catalyst layer with nanowire supported catalysts (Figure 6A). In contrast, large ionomer agglomerates can be observed in the catalyst layer with carbon supported catalysts (Figure 6B). These features result in a higher triple-phase boundary area for the nanowire supported catalysts over the carbon supported catalysts, and hence higher catalyst utilization of nanowire supported catalysts gives a high fuel cell performance.

A direct painted MEA fabrication method has been developed in Task 4.0. Catalyst and ionomer distribution in MEA have been characterized by SEM and TEM and compared with commercial carbon supported catalyst. The catalyst loading in MEA is controlled in a range of 1 to $3 \mathrm{mg} / \mathrm{cm}^{2}$.

\section{Task 5.0: Single Cell Fabrication}

Using the MEA from Task 4.0, a single cell is assembled using a commercially available fuel cell fixture (Fuel Cell Technologies). Anode polarization and fuel cell polarization performance have been evaluated, respectively. To compare and evaluate the nanowire anode catalyst, a commercial $\mathrm{Pt} / \mathrm{C}$ cathode catalyst is used. Cathode polarization behavior has been evaluated to ensure cathode performance comparable in different cells with different anode catalysts.

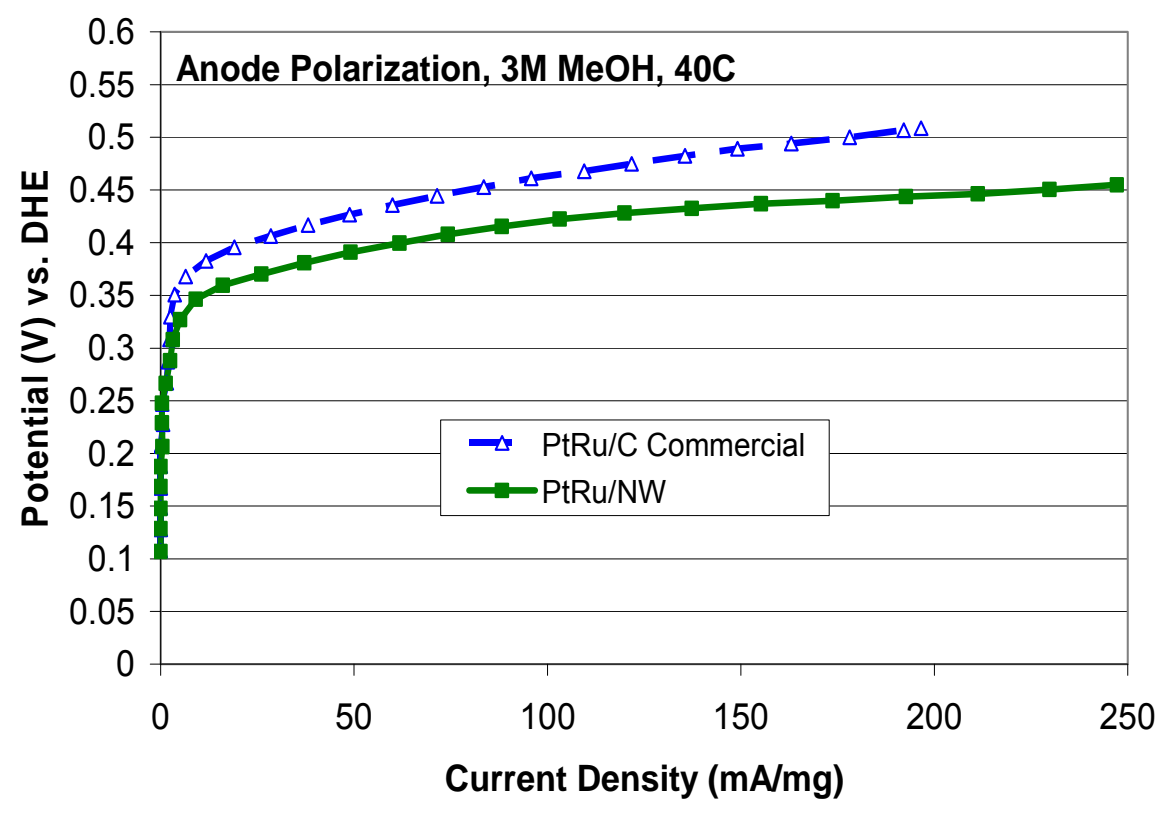


Figure 7 Anode polarizations (AP) for methanol oxidation on fuel cell anode, PtRu/NW (Nanosys) vs. PtRu/C (commercial).

As for the anode polarization performance, experimental data indicate performance improvement by nanowire catalyst. The anode in MEA made with nanowire catalyst shows that the performance improvement in anode polarization is ca. $47 \mathrm{mV}$ at $100 \mathrm{~mA} / \mathrm{mg}-\mathrm{PtRu}$ and $71 \mathrm{mV}$ at $200 \mathrm{~mA} / \mathrm{mg}-\mathrm{PtRu}$, as shown in Figure 7. At present, we have achieved a maximum power density of $112 \mathrm{~W} / \mathrm{cm}^{2}$ in DMFC with nanowire anode catalyst and $3 \mathrm{M}$ methanol at $40^{\circ} \mathrm{C}$, which is $45 \mathrm{~mW} / \mathrm{cm}^{2}$ higher than that with commercial PtRu/C anode catalyst (Figure 8). A high power density of $86 \mathrm{~mW} / \mathrm{cm}^{2}$ achieved at $0.4 \mathrm{~V}$.

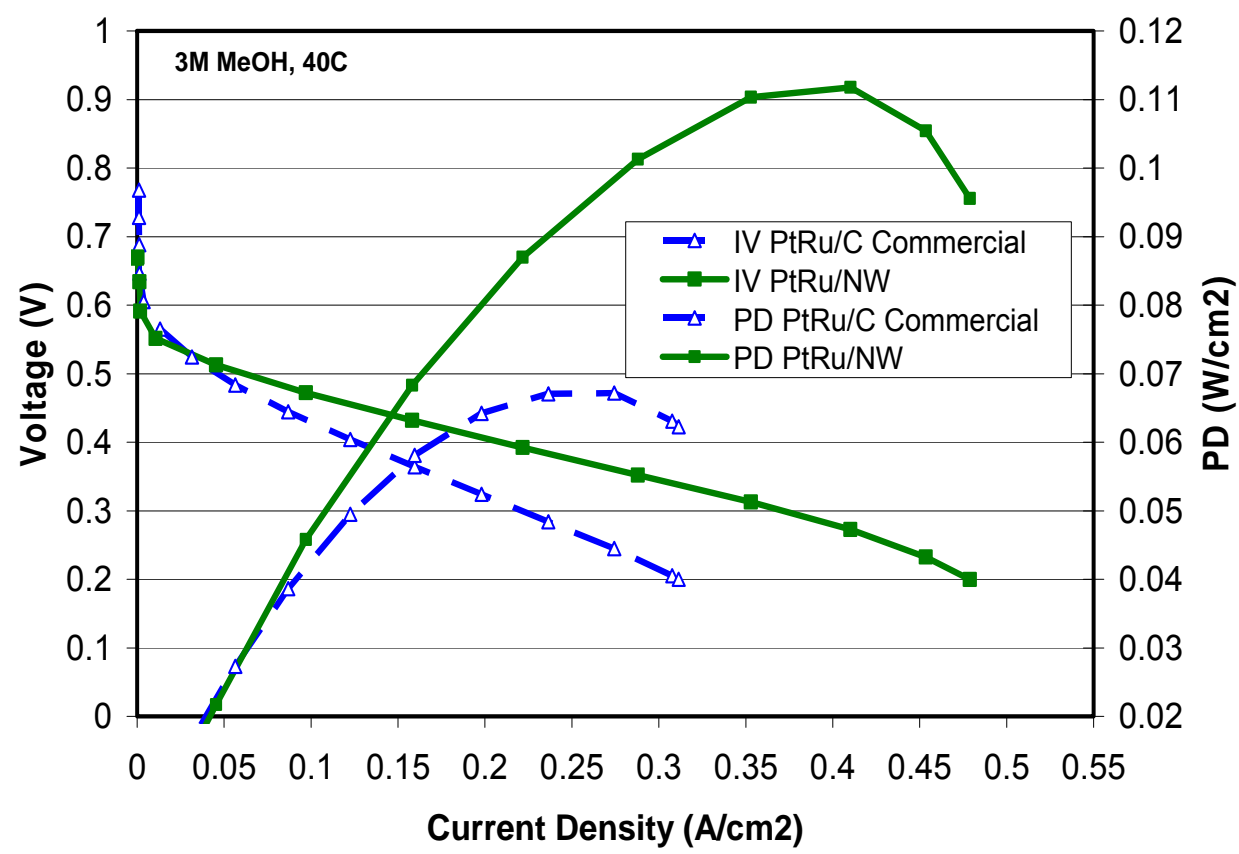

Figure 8 Fuel cell polarization curve and power density curve. PtRu/NW (Nanosys) vs. PtRu/C (commercial).

Task 5.0 has been completed. We demonstrated the feasibility of constructing a fuel cell device using the MEA with nanowire catalysts. We achieved a power density that significantly exceeds MEA using commercially available catalysts/supports (ca.68 $\left.\mathrm{mW} / \mathrm{cm}^{2}\right)$.

In summary, nanowire supported catalyst has advantages over commercial carbon supported catalyst, which are high catalyst utilization (1.6x $>\mathrm{PtRu} / \mathrm{C})$, high activity (2.6x> PtRu/C), high accessibility, and high stability/durability, as shown in Table 2. These differentiate nanowire based catalyst from carbon supported catalyst. 
Table 2 nanowire supported catalyst advantages

\begin{tabular}{|c|c|c|c|c|}
\hline 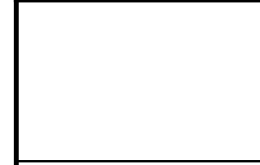 & $\begin{array}{c}\text { TPB Area } \\
\left(\mathrm{m}^{2} / \mathrm{g}\right)\end{array}$ & \begin{tabular}{|c|} 
Catalyst \\
Utilization (\%)
\end{tabular} & $\begin{array}{c}\mathrm{AP}, \mathrm{I} \\
(\mathrm{mA} / \mathrm{mg}) @ \\
0.45 \mathrm{~V}, 40^{\circ} \mathrm{C}\end{array}$ & $\begin{array}{c}\mathrm{AP}, \mathrm{I} \\
(\mathrm{mA} / \mathrm{mg}) @ \\
0.3 \mathrm{~V}, 40^{\circ} \mathrm{C}\end{array}$ \\
\hline $\begin{array}{l}\text { Nanosys } \\
\text { PtRu/Nanowire }\end{array}$ & 47 & 61 & 260 & 9.8 \\
\hline $\begin{array}{l}\text { Commercial } \\
\text { PtRu/Carbon }\end{array}$ & 23 & 39 & 76 & 3.8 \\
\hline
\end{tabular}

For anode polarization, the mass current of PtRu/NW is 3.4 times higher than that of $\mathrm{PtRu} / \mathrm{C}$ at $0.45 \mathrm{~V}, 40^{\circ} \mathrm{C}$. This mass current is attributed to improvement in both activity and accessibility. In contrast, at lower potential of $0.3 \mathrm{~V}$, the activity-dominant mass current for PtRu/NW is 2.6 times higher that of PtRu/C. The difference in mass current gain between $0.45 \mathrm{~V}$ and $0.3 \mathrm{~V}$ is an indication of improvement in accessability for PtRu/NW.

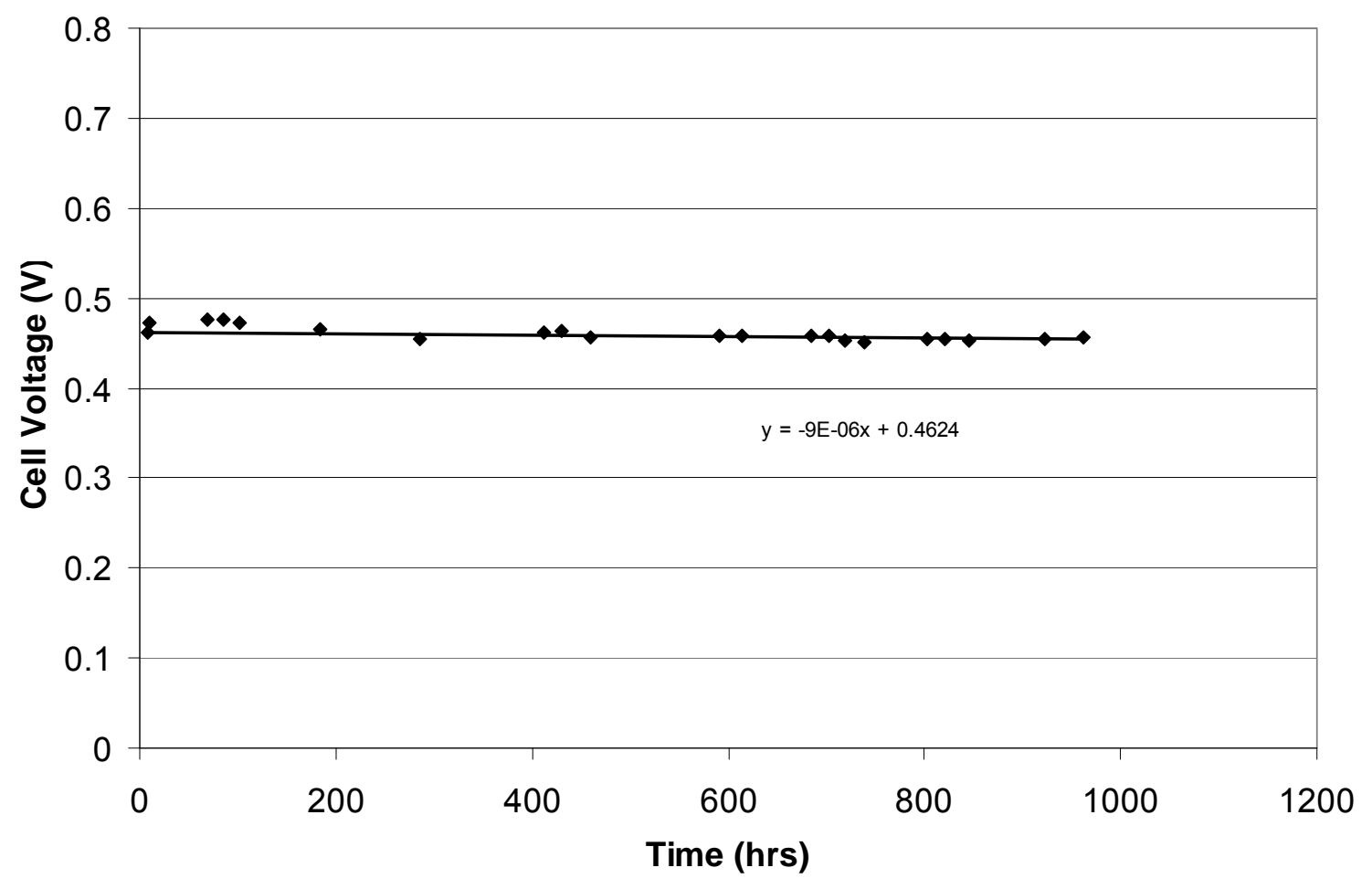

Figure 9 Durability of the MEA with PtRu/NW anode catalyst, 3M methanol solution and ambient air, at $40^{\circ} \mathrm{C}$.

In addition, we achieved durability of over 1,000 hours with $9 \mathrm{uV} / \mathrm{hr}$ decay rate, by operated the DMFC with $3 \mathrm{M} \mathrm{MeOH}$ and ambient air at $40^{\circ} \mathrm{C}$. 


\section{Conclusions and Future Directions}

Nanosys has developed durable fuel cell catalysts, which outperform the state of the art catalysts:

The project demonstrated novel inorganic nanowire catalyst support and catalysts. This may fundamentally overcome the catalyst durability problems, in particular, carbon corrosion problem.

Unique features of the nanowire supported catalysts are firstly demonstrated for methanol oxidation prior to hydrogen oxidation. It turned out that PtRu/NW catalysts have higher activity, utilization and accessibility over commercial PtRu/C catalysts. nanowire supported catalysts have superior stability over carbon supported catalysts.

The results have been presented in 2009 Small Fuel Cells and 2009 DOE annual Review Meeting.

We have also fulfilled reporting obligations and prepare manuscripts for publications. As for future directions, we will explore further applications in hydrogen fuel cells and develop more active catalysts for cathode. (This effort will continue at Nanosys after completion of the project.)

\section{Patents:}

Nanostructured Catalyst Supports, 01-007440US, filed in April of 2009, Yimin Zhu, Jay Goldman, Baixin Qian and lonel Stefan, portions of this invention may have been made pursuant to a contract with the US DOE, Hydrogen, Fuel Cells \& Infrastructure Technologies Program Contract Number DE-FG36-08G088097

\section{Publications / Presentations:}

1. DMFC Inorganic-Nano-Fiber-Based Catalyst with Superior Performance and Lifetime Yimin Zhu, Ionel Stefan, Baixin Qian, Jay Goldman, Jurgen Hofler and Jason Hartlove, 11th Annual International Conference for Small Fuel Cells 2009: Portable \& Micro Fuel Cells for Commercial and Military Applications - May 7-8, 2009

2. Engineered Nanostructured MEA Technology for Low Temperature Fuel Cells Yimin Zhu, Ionel Stefan, Baixin Qian, Jay Goldman, Jurgen Hofler and Jason Hartlove, 2009 DOE ANNUAL MERIT REVIEW and PEER EVALUATION MEETING, May 18, 2009; fcp_09_zhu 


\section{Task Schedule}

\begin{tabular}{|c|c|c|c|c|c|c|}
\hline \multirow[b]{2}{*}{$\begin{array}{l}\text { Task } \\
\text { Number }\end{array}$} & \multirow[b]{2}{*}{ Project Milestones } & \multicolumn{4}{|c|}{ Task Completion Date } & \multirow[b]{2}{*}{ Progress Notes } \\
\hline & & $\begin{array}{l}\text { Original } \\
\text { Planned }\end{array}$ & $\begin{array}{l}\text { Revised } \\
\text { Planned }\end{array}$ & Actual & $\begin{array}{l}\text { Percent } \\
\text { Complete }\end{array}$ & \\
\hline 1 & $\begin{array}{c}\text { Nanowires with high } \\
\text { surface area (target: } \\
>100 \mathrm{~m}^{2} / \mathrm{g} \text { ) and high } \\
\text { conductivity }\end{array}$ & 2/28/09 & & $3 / 31 / 09$ & $100 \%$ & Complete \\
\hline 2 & \begin{tabular}{|} 
Catalyst nanoparticles \\
with a size range of 1 to \\
$5 \mathrm{~nm}$ \\
\end{tabular} & 2/28/09 & & $12 / 31 / 08$ & $100 \%$ & Complete. \\
\hline 3 & $\begin{array}{c}\text { Catalyst Integration onto } \\
\text { nanowire support with } \\
\text { improved stability and } \\
\text { activity } \\
\end{array}$ & $8 / 20 / 09$ & & $3 / 31 / 09$ & $100 \%$ & Complete. \\
\hline 4 & $\begin{array}{c}\text { MEA Development and } \\
\text { Characterization }\end{array}$ & 8/20/09 & & 7/10/09 & $100 \%$ & Complete. \\
\hline 5 & $\begin{array}{c}\text { Single Cell Fabrication } \\
\text { and power density }>60 \\
\mathrm{~mW} / \mathrm{cm}^{2}\end{array}$ & $8 / 20 / 09$ & & $7 / 10 / 09$ & $100 \%$ & Complete. \\
\hline 6 & Project Management & 8/20/09 & & 7/13/09 & $100 \%$ & Complete \\
\hline
\end{tabular}

